\title{
Flood Management at Narrow River Mouth
}

\author{
Omar Seleem ${ }^{1, *}$, Akihiro Kadota ${ }^{1}$, and Pratiwi Aziz ${ }^{1}$ \\ ${ }^{1}$ Civil \& Environmental Engineering Department, Ehime University, Japan
}

\begin{abstract}
Hiji River is characterized by many tributaries, low bed gradient, and narrow river mouth. Due to these characteristics, several floods occurred in the past. The narrow river mouth is the main reason of flood occurrence in Hiji River. The current study is focusing on the rainfall event which caused massive damage in 2004. The purpose of the current study is to update the existing hazardous map and compare the simulation results obtained from International River Interface Cooperative (iRIC) with the measured data to calibrate the model. The simulation was carried out using Nays2DH within the measured data record from Japan Ministry of Land, Infrastructure, and Transport. The analysis result was compared with the inundated areas and almost have the same results.
\end{abstract}

\section{Introduction}

Recently, as a result of global warming, Japan is affected by an increase in temperature, massive typhoons, and torrential rains. Also, the frequency of occurrence of a natural disaster such as flood, typhoon, and tsunami is increasing [1]. Also, due to urbanization of Hiji River watershed, massive losses in lives and properties are expected in case of occurring of natural disaster.

Floods can be counted as the most destructive natural disaster as floods have occurrence frequency higher than any other natural hazard. In addition to this point, floods are affecting more people than all the other natural hazards combined together [2]. Recently, flood simulation models have been remarkably developed and used widely to simulate floodplains and flood losses estimation. A variety of analytical models developed for different scales and purposes [3]. These models are able to accurately analysis river morphology and geometry by considering the necessary flood countermeasures for predicting flood patterns [4].

Hiji River is the largest river in Ehime Prefecture, Japan. It is located in North West of Shikoku Island which is the smallest island of Japan's four main islands. Hiji River is passing through Ozu city, Ehime Prefecture, Japan. The city area is $432.2 \mathrm{~km}^{2}$. The city had a population of 48,000 capita in 2012. Hiji river length is about $103 \mathrm{~km}$, and the river watershed is about $1210 \mathrm{~km}^{2}$ as shown in Figure 1. The average annual rainfall is $1800 \mathrm{~mm}$. The river is characterized by narrow mouth and several tributaries as shown in Figure 2. The narrow mouth caused several flood disasters. Table 1 shows the destruction from floods. In addition, flood destruction was particularly massive in the east Ozu city at the intersection area between Yaochi River and Hiji River.

\footnotetext{
*Corresponding author: omar abdelwahab92@,yahoo.com
} 
It is obvious from Table 1 that typhoon number 16 caused the largest recorded damage. Therefore, the current study is focusing on the flood event occurred from it. During this event, most of the flooded area was concentrated in the west part of Ozu city, thus detailed twodimensional model (2D model) was performed for this area.

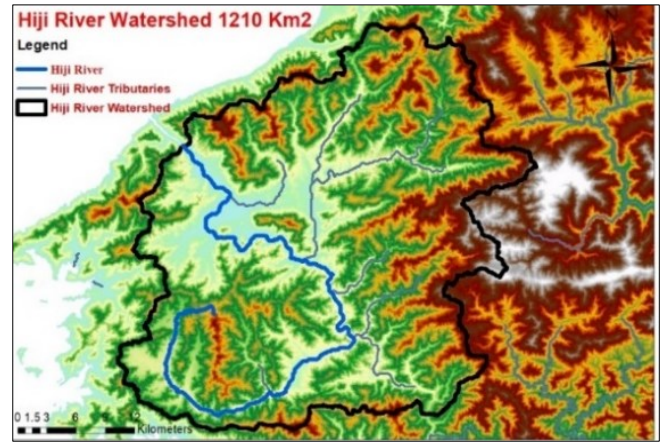

Fig. 1. Hiji River Watershed.

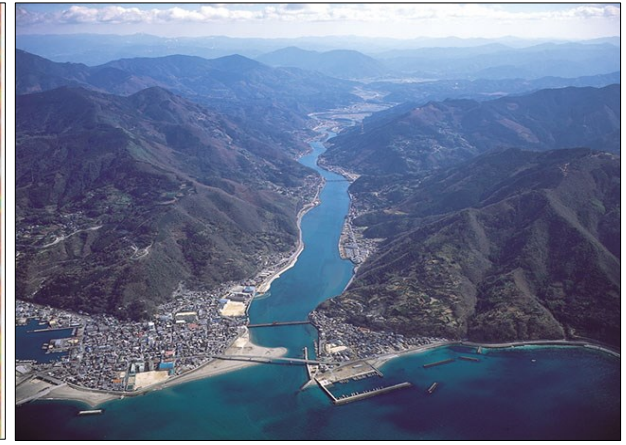

Fig. 2. Hiji River Narrow Mouth.

Table 1. Past Flood Destruction.

\begin{tabular}{|c|c|c|c|}
\hline \multirow{2}{*}{ Date } & Cause & $\begin{array}{c}\text { Flow } \\
\text { Discharge } \\
\left(\mathbf{m}^{3} / \mathbf{s e c}\right)\end{array}$ & Recorded Damage \\
\hline $31 / 08 / 2004$ & $\begin{array}{c}\text { Typhoon } \\
\text { number 16 }\end{array}$ & 3200 & 277 residential building destroyed \\
\cline { 4 - 4 } $229 / 09 / 2004$ & $\begin{array}{c}\text { Typhoon } \\
\text { number 21 }\end{array}$ & 2300 & 38 residential building destroyed \\
\hline $20 / 10 / 2004$ & $\begin{array}{c}\text { Typhoon } \\
\text { number 23 }\end{array}$ & 2100 & 9 residential building destroyed \\
\hline $06 / 09 / 2005$ & $\begin{array}{c}\text { Typhoon } \\
\text { number 14 }\end{array}$ & 3300 & inundation area about 713 ha \\
\cline { 4 - 4 } $21 / 09 / 2011$ & $\begin{array}{c}\text { Typhoon } \\
\text { number 15 }\end{array}$ & 3200 & 167 residential building destroyed \\
\cline { 4 - 4 } & & & Inundation area 574 ha \\
\hline
\end{tabular}

\section{Methodology}

This study simulates the flood event occurred due to typhoon number 16 as it has the largest recorded damage. The flood occurred at the intersection area between Yaochi River and Hiji River. The simulation was performed using iRIC.

iRIC is an analysis software for river flow and riverbed variation which combines MultiDimensional Surface-Water Modeling System (MD_SWMS) developed by U.S. Geological Survey (USGS) and River Interface Corporative (RIC Nays) developed by the Foundation of Hokkaido River Disaster Prevention Research Center. iRIC included Nays 2D, Morpho 2D, FaSTMECH, etc. as a planar two-dimensional solver with the increased. In here, Nays2DH was using as the developed from Nays2D. Nays 2DH is a planar two-dimensional solver developed to calculate the flow in the river, river bed change, and river bank erosion. The general step of performing a simulation is creating a grid for calculation using river survey data and/or Digital Elevation Model (DEM) data; set simulation discharge, boundary conditions, roughness and other items then finally run the simulation. 


\subsection{Input data}

\subsubsection{Digital Elevation Model}

Topographic data were obtained from the topographic generated data by NASA's Shuttle Radar Topography Mission (SRTM) project, which is collecting topographic data over about $80 \%$ of earth land surfaces. SRTM was a joint project between National Aeronautics and Space Administration (NASA), National Geospatial-Intelligence Agency (NGA) and the Italian and German space agencies. SRTM grant free topographic data sampled at 3 arcseconds (90 meters) and 1 arc-seconds (30 meters). The obtained topographic data was used to delineate the river watershed and also for the 2D modeling as shown in Figure 3. In order to get more accuracy, a grid of $5 \mathrm{~m}$ spacing was received for the study area are shown in Figure 4 and the study area is shown in Figure 5.

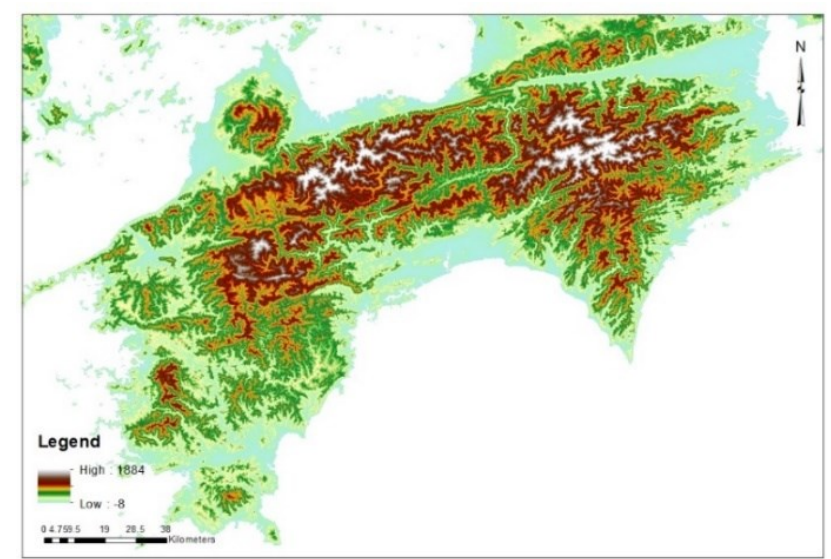

Fig. 3. Shikoku Island SRTM Data.

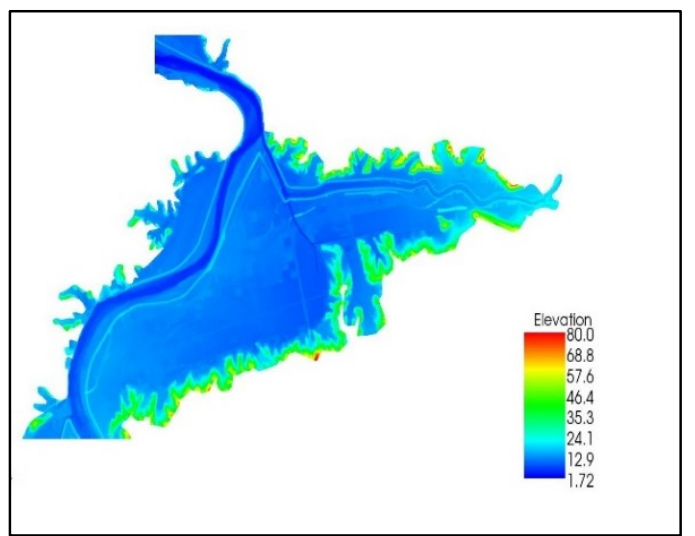

Fig. 4. Measured Topographic Data for west Ozu City.

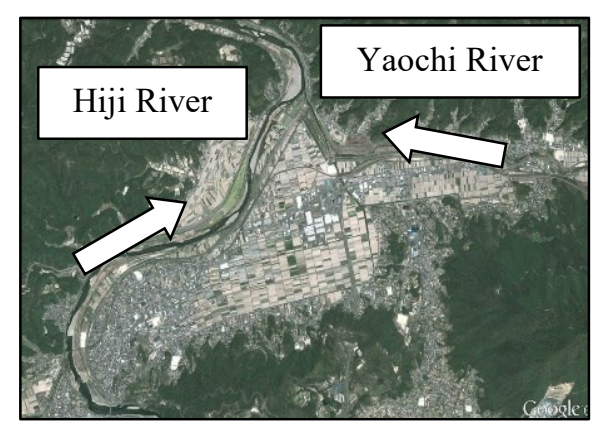

Fig. 5. Study Area.

\subsubsection{Flow Data}

In the current study, the flood started from Yaochi River then it overflowed the existing levee to the inland. Figure 6 and Figure 7 show the obtained flow hydrographs. Figure 6 demonstrates that the flow time is about 6 hours 29 minutes. The overflow started on $30^{\text {th }}$ of August 2004 from 22:15 until $31^{\text {st }}$ of August to 04:44. The flow data is the outdoor flooding 
from the interim levees. The overflow is started on $30^{\text {th }}$ August 2004 at 18:00 until $31^{\text {st }}$ August 2004 at 05:00. The flow data is the inland water flooding from Miyako River. The inundation situation on August 2004 is shown in Figure 8.

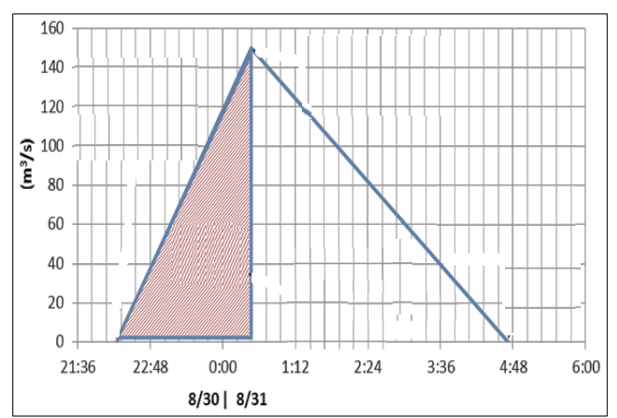

Fig. 6. Overview of outdoor flooding analysis.

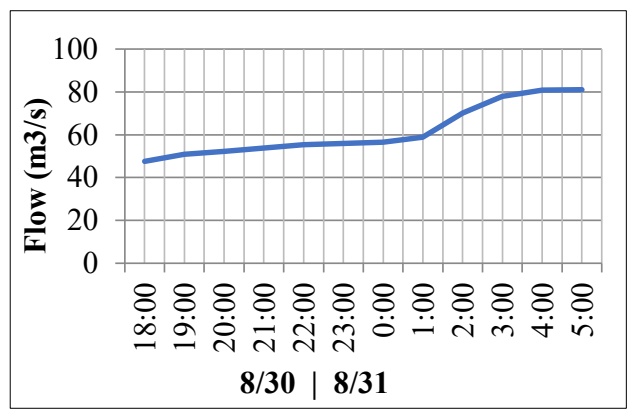

Fig. 7. Outline of inland water flooding analysis.

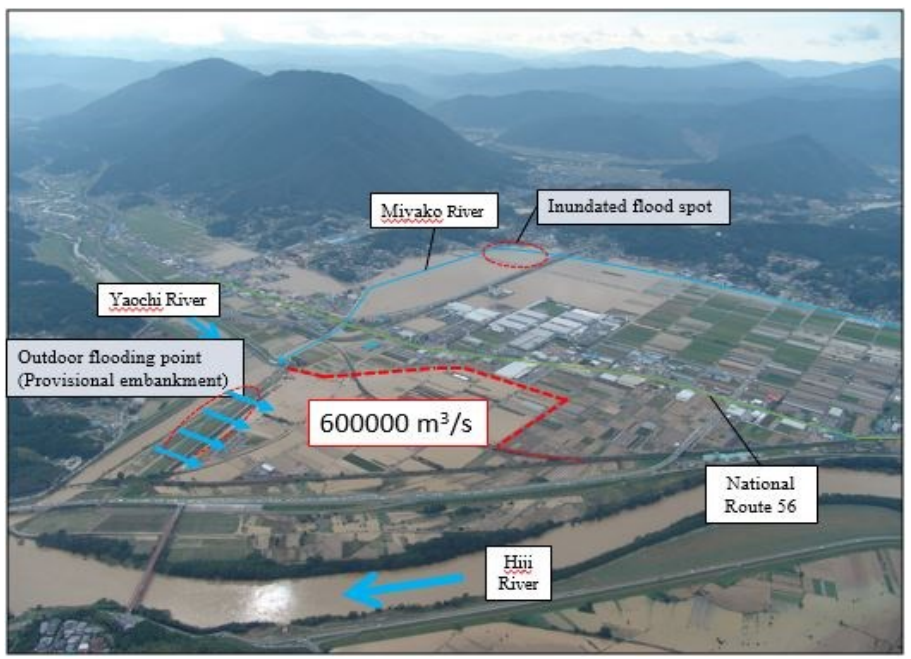

Fig. 8. Inundation situation on August 2004

\subsubsection{Roughness}

The roughness coefficient was set according to Japan Ministry of Land, infrastructure, and transportation. The roughness values were set to be 0.035 for river channel, 0.05 for floodplain and 0.08 for the vegetation area.

In order to calculate the land use of each mesh cell. The land use is divided into three categories: building; farmlands $A_{1}$, Road $A_{2}$ and other land use $A_{3}$. Then the roughness coefficient is weighted average by using equation 1 .

$$
n_{0}^{2}=\frac{n_{1}{ }^{2} A_{1}+n_{2}{ }^{2} A_{2}+n_{3}{ }^{2} A_{3}}{A_{1}+A_{2}+A_{3}}
$$

Where, $\mathrm{n}_{1}=0.06, \mathrm{n}_{2}=0.047, \mathrm{n}_{3}=0.050$

The composite land and buildings equivalent roughness coefficient is calculated by equation 2 .

$$
n^{2}=n_{0}^{2}+0.020 \times \frac{\theta}{100-\theta} \times h^{4 / 3}
$$


Where $\theta$ is the proportion of land occupied by buildings and $\mathrm{h}$ is water depth.

\section{Results}

In the current study, the simulation models were done to simulate the occurred flood event. The model was simulated the flooding from Yaochi River that occurred due to the typhoon number 16 which has the largest recorded damage. The flood starts on $30^{\text {th }}$ of August until $31^{\text {st }}$ of August at 5:00. The analysis result diagram of inundation area is shown in Figure 9.

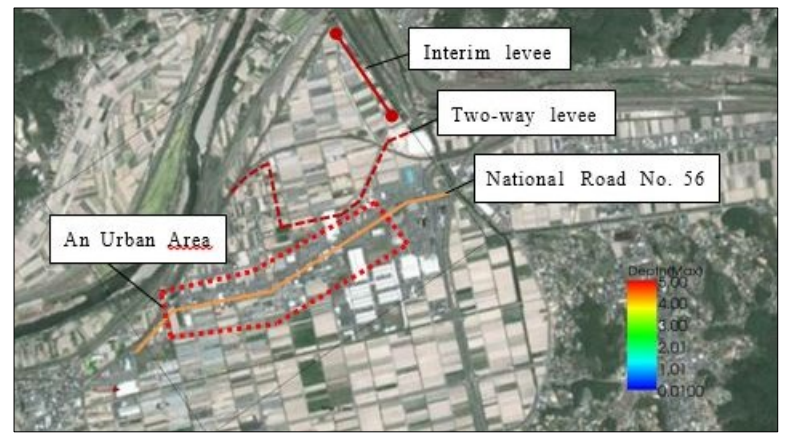

Fig. 9.a Analysis Result Diagram (after 0 hour on $30^{\text {th }}$ August at 22:15

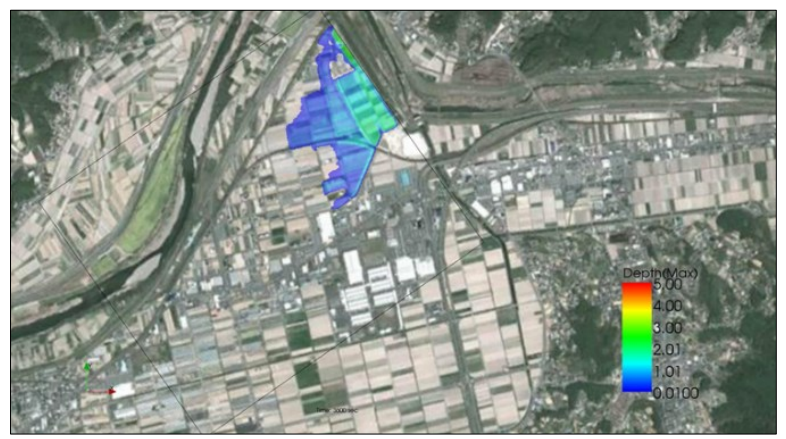

Fig. 9.b Analysis Result Diagram (after 1 hour on $30^{\text {th }}$ August at 23:15

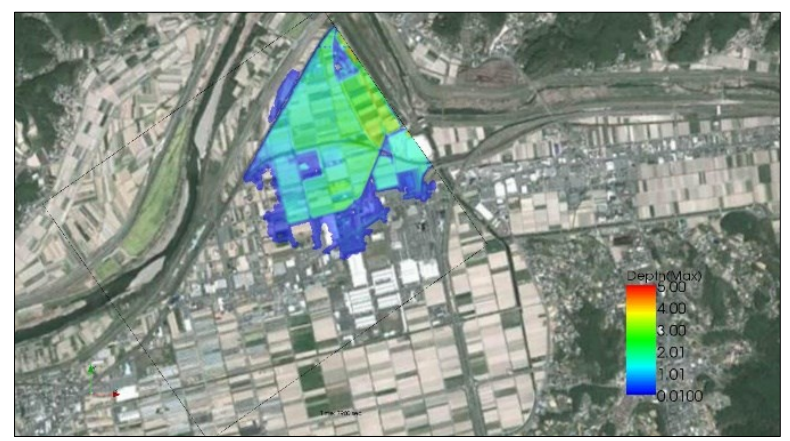

Fig. 9.c Analysis Result Diagram (after 2 hour 13 minutes on $30^{\text {th }}$ August at 00:28 


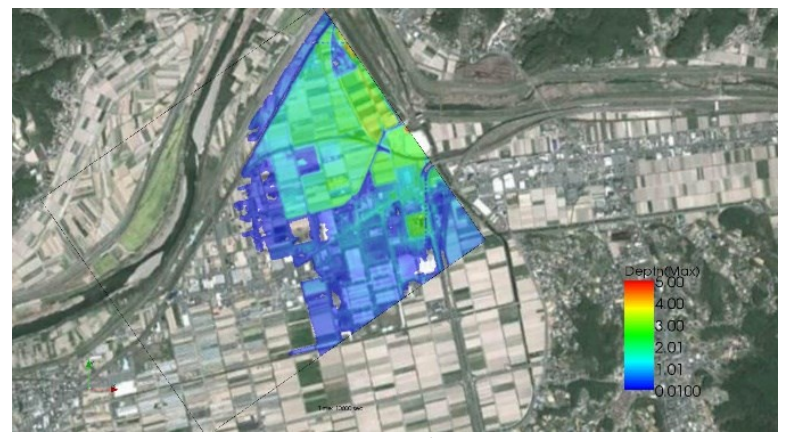

Fig. 9.d Analysis Result Diagram (after 3 hour on $31^{\text {st }}$ August at 01:15

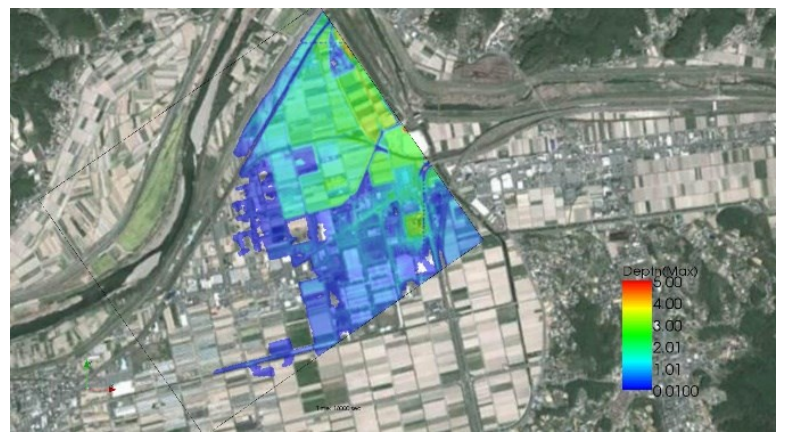

Fig. 9.e Analysis Result Diagram (after 5 hour on $31^{\text {st }}$ August at 03:15

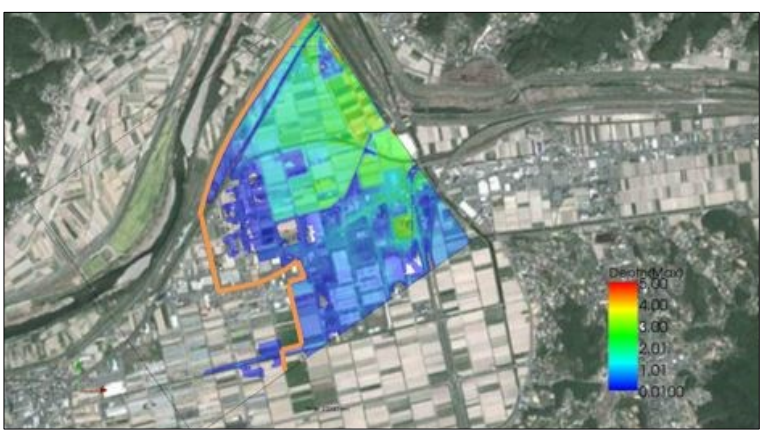

Fig. 9.f Analysis Result Diagram (after 6 hour 29 minutes on $31^{\text {st }}$ August at 04:44

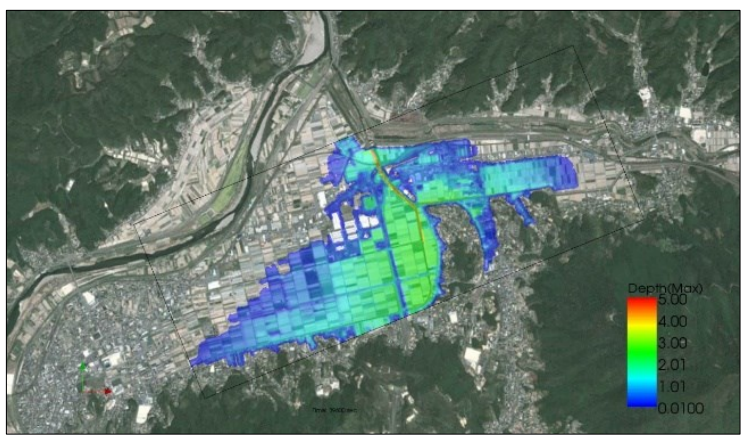

Fig. 9.g Analysis Result Diagram Final on $31^{\text {st }}$ August at 05:00

Fig. 9. Analysis Result Diagram of Inundation Area 
Starting with Figure 9.a, it shows the situation before the overflow. Moving on, Figure 9.b shows the situation when the overflow is starting through the interim levee, and Figure 9.c shows that the overflow begins from the levee. Furthermore, Figure 9.d and Figure 9.e are describing the showing the floodplain while Figure 9.f the overflow of the temporary breakwater was ended. Finally, Figure 9.g shows the final inundation that carried out. We can witness from the figures that the obtained floodplain and flooding depth from the simulation are similar to what happened which shows that almost accurate simulation result was obtained.

\section{Conclusion}

The simulation shows that study area need flood protection countermeasures, especially from the Yaochi River. It is recommended to maintain the existing levee at Yaochi River in order to protect this area from a future flood. It is necessary to analyze both internal and external water at the same time.

The simulation also shows that the drainage system needs maintenance and improvement in order to be able to drain the rainwater efficiently with taking into consideration typhoon events. It is recommended for future studies to simulate the flood along all Hiji river and increase the accuracy of the analysis by detailed topographic data.

\section{References}

1. T. Das, EP. Maurer, P. David W., MD. Dettinger, DR. Cayan. Increases in flood magnitudes in California under warming climates. J Hydrol 501:101-10 (2013)

2. Asia Disaster Reduction Center (ARDC). Natural disaster data book 2009 (an analytical review), Kobe, Japan; p. 23, (2009).

3. Sampson, C.C., Smith, A.M., Bates, P.D., Neal, J.C., Alfieri, L., Freer, J.E., A high resolution global flood hazard model. Water Resource. Res. 51, 7358-7381 (2015)

4. T.J Fewtrell, A. Duncan, C.C Sampson, J.C. Neal, P.D. Bates, Benchmarking urban flood models of varying complexity and scale using high resolution terrestrial LiDAR data. Phys. Chem. Earth Parts A/B/C 36, 281-29 (2011). 